\title{
Response to "A comment on 'Osteosarcopenia: A Geriatric Giant of the XXI Century"
}

\section{G. Duque}

Australian Institute for Musculoskeletal Science (AIMSS), The University of Melbourne and Western Health, Melbourne, Australia

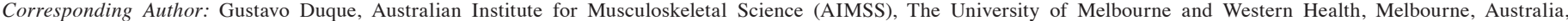
gustavo.duque@unimelb.edu.au

\section{Dear Editor,}

I $\mathrm{n}$ their comment to my recent Editorial entitled 'Osteosarcopenia: A Geriatric Giant of the XXI Century" (1), the authors narrowed their observations to the epidemiological aspects of this recently described geriatric syndrome. An important consideration the authors failed to mention is that all four prospective cohort studies and the cross-sectional study cited in their comment used DXA-derived lean mass measurements in the definitions of osteosarcopenia/ sarcopenia. Despite our recommendation to use DXA-lean mass in the osteosarcopenia definitions due to its wide use in clinical settings (2), we are aware that DXA-lean mass is a surrogate measure of muscle mass and not an accurate measure when compared to other imaging modalities (MRI/pQCT/ HR-pQCT) (3). Indeed, recent work from the Osteoporotic Fractures in Men Study ( $\mathrm{n}=1,425$, age 77-101 years) showed that while accurate measures of muscle mass (measured by creatine dilution) are strongly associated with incident mobility disability, falls and mortality, DXA-appendicular lean mass (including adjustments for height squared and BMI) are not (4, $5)$. Thus, the prospective cohort studies cited in the comment have not tested the interactions using accurate measures of muscle mass with bone density/structure. Given the wellknown mechanical and metabolic relationship between muscle and bone, there is a strong biological rationale to test this hypothesis through a robust longitudinal study design, as we have previously suggested $(1,2)$. Still, based on currently available evidence, multiple groups worldwide (including ours) are investigating whether osteosarcopenia implies a greater risk of fractures, mortality, and falls (6), a question that deserves further exploration and that highlights the importance of identifying these two conditions in clinical practice, while understanding the limitations of current studies and looking forward to the results of several ongoing longitudinal cohorts in the field, which are using more accurate and sensitive structural and clinical methods to identify osteopenia/osteoporosis and sarcopenia in older persons.

A particularly concerning element of this comment is the authors" indistinguishable use of the terms "disease" and "geriatric syndrome". The concept of geriatric syndromes, which is universally taught during early training years in geriatric medicine, is defined as "highly prevalent in older persons, multifactorial, and associated with substantial morbidity and poor outcomes" (7), which is clearly the case of osteosarcopenia, a syndrome whose recognition has been affected by research and clinical silos and fragmented models of care. The intention of the Editorial was not to "create a new disease" as stated by the authors, which is unnecessary considering that both osteoporosis and sarcopenia are wellrecognised diseases, but to increase awareness of the existence of a geriatric syndrome (Geriatric Giant) that "could become the unifier concept that will finally improve care to these devastating conditions".

Conflict of interest: No conflict of interest to declare.

\section{References}

1. Duque G. Osteosarcopenia: A Geriatric Giant of the XXI Century. J Nutr Health Aging. 2021;25(6):716-719

2. Kirk B, Zanker J, Duque G. Osteosarcopenia: epidemiology, diagnosis, and treatmentfacts and numbers. J Cachexia Sarcopenia Muscle. 2020;11(3):609-618.

3. Buckinx F, Landi F, Cesari M, Fielding RA, Visser M, Engelke K, Maggi S, Dennison E, Al-Daghri NM, Allepaerts S, Bauer J, Bautmans I, Brandi ML, Bruyère O, Cederholm T, Cerreta F, Cherubini A, Cooper C, Cruz-Jentoft A, McCloskey E, Dawson-Hughes B, Kaufman JM, Laslop A, Petermans J, Reginster JY, Rizzoli R, Robinson S, Rolland Y, Rueda R, Vellas B, Kanis JA. Pitfalls in the measurement of muscle mass: a need for a reference standard. J Cachexia Sarcopenia Muscle. 2018;9(2):269-278.

4. Cawthon PM, Blackwell T, Cummings SR, et al. Muscle Mass Assessed by the D3-Creatine Dilution Method and Incident Self-reported Disability and Mortality in a Prospective Observational Study of Community-Dwelling Older Men. J Gerontol A Biol Sci Med Sci. 2021;76(1):123-130.

5. Cawthon PM, Orwoll ES, Peters KE, Ensrud KE, Cauley JA, Kado DM, Stefanick ML, Shikany JM, Strotmeyer ES, Glynn NW, Caserotti P, Shankaran M, Hellerstein M, Cummings SR, Evans WJ; Osteoporotic Fractures in Men (MrOS) Study Research Group. Strong Relation Between Muscle Mass Determined by D3-creatine Dilution, Physical Performance, and Incidence of Falls and Mobility Limitations in a Prospective Cohort of Older Men. J Gerontol A Biol Sci Med Sci. 2019;74(6):844852.

6. Teng Z, Zhu Y, Teng Y, Long Q, Hao Q, Yu X, Yang L, Lv Y, Liu J, Zeng Y, Lu S The analysis of osteosarcopenia as a risk factor for fractures, mortality, and falls. Osteoporos Int. 2021 Apr 20.

7. Inouye SK, Studenski S, Tinetti ME, Kuchel GA. Geriatric syndromes: clinical, research, and policy implications of a core geriatric concept. J Am Geriatr Soc. 2007;55:780-791.

How to cite this article: G. Duque. Response to "A comment on 'Osteosarcopenia: A Geriatric Giant of the XXI Century". J Nutr Health Aging. 2021;25(7):948; http:// dx.doi.org/10.1007/s12603-021-1661-z 